\title{
An Innovative Design of Vibratory Feeding System for Teaching Purpose
}

\author{
Liang $\mathrm{Han}^{\mathrm{a}}$, Ye Guo \\ School of Mechanical Engineering, Southeast University \\ Jiangning District, NanJing 211189, China \\ amelhan@seu.edu.cn, bgyqdxy@163.com
}

Keywords: Vibratory Feeding; Teaching; System; Industry Applications; Working Principle

\begin{abstract}
Vibratory feeding plays a key role in assembly automation. However, there is still no effective professional instrument to explain and demonstrate the principle of the parts conveying. Thus an innovative vibratory feeding system for teaching purpose is designed in this paper, which includes the demo device of industry application and demo device of working principle. The demo device of industry application consists of vibratory bowl feeder and linear vibratory feeder, which realizes the automatic feeding and orientation of the work-piece. This device makes the industry application of vibratory feeding more intuitive. And the parameters of demo device of working principle can be adjusted for demonstrating the principle of vibratory feeding.
\end{abstract}

\section{Introduction}

After the concept of vibratory feeder is proposed, some contributions have been made to the principle analysis of the feeder. De Cock ${ }^{[1]}$ firstly proposed the parameterized analysis of feeder. Winkler ${ }^{[2][3]}$ analyzed the part motion and proposed the fundamental theory of part sliding and jumping movement. Yokoyama ${ }^{[4]}$ developed a one-degree-of-freedom model of vibratory bowl feeders resulting in a simple formula for the computation of a single natural frequency. Okabe ${ }^{[5]}$ put forward the influence of vibration waveform to the conveying velocity, but he also discovered the uncertainty of sensor to vibration waveform. G. H. Lim $^{[6][7]}$ did research on the conveying velocity of the parts and modeling of the feeder. Brian Thomas ${ }^{[8]}$ presented a six-degree-of-freedom model that could predict the motion of the bowl using state-space methods. Chao, Shen ${ }^{[9]}$ made modeling and analysis of piezoelectric ceramic feeder. In addition, Bangchun Wen of Chinese Academy of Sciences ${ }^{[10]}$ and his team have done in-depth research and analysis on work-piece transfer theory and work-piece's state of motion. But at present, teaching of vibratory feeding is introduced by way of words or pictures, which makes the process more abstract, and not easy to understand. Some colleges which have better conditions use industry feeder as teaching instrument to do vibratory feeding demonstration, but industry feeder used for teaching has following shortcomings: large volume, hard to move, demonstration of vibratory feeding is not a systematic, and once the mechanical structure is done, the parameters cannot be changed. Based on the above analysis, this paper designs an innovative vibratory feeding system, which includes the demo device of industry application and demo device of working principle. Demo device of industry application consists of vibratory bowl feeder and linear vibratory feeder, which realizes the automatic feeding and orientation of the work-piece. This device makes the industry application of vibratory feeding more intuitive. And demo device of working principle helps the oriented work-piece moving forward, until arriving to the next the procedure. Based on linear vibratory feeder, the parameters (including track angle $\alpha$, vibration angle $\beta$, frictional coefficient $\mu$ ) of the demo device of working principle can be adjusted for the study of the conveying of parts. And the demo device of working principle provides an effective professional instrument to explain and demonstrate the principle of the parts conveying.

\section{Working principle}

Vibratory feeder is a typical product which applies the technology of vibratory feeding to the 
industrial automation control system, and its main principle is to directionally arrange work-pieces in disorder and transfer them to the next working procedure with the tray driven by the vibration generated by the electromagnet, piezoelectric crystal slice or piezoelectric ceramic piece. It can assemble every part into a complete production together with the automatic assembly line. As an auxiliary device in the automatic assembly line, vibratory bowl feeder is mostly used for these little parts that have certain shapes and sizes and need to be arranged orientated. Fig. 1 shows its structure.

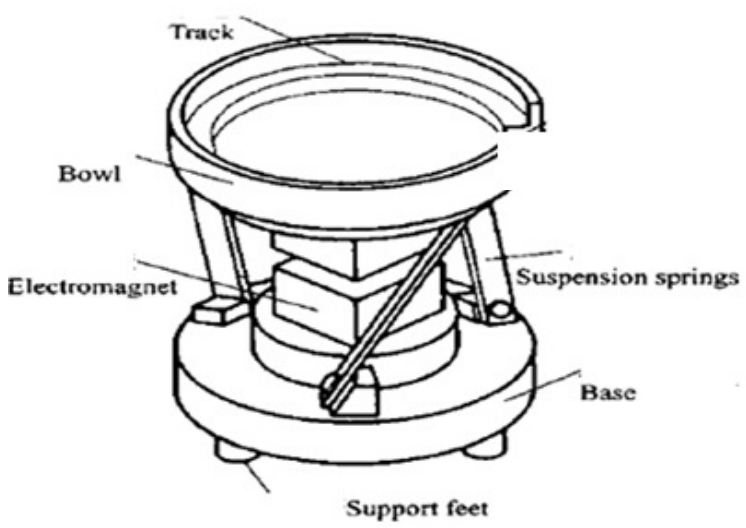

Fig.1 Structural schematic diagram of the vibratory bowl feeder

\section{Design of the demo device of industry application}

Vibratory feeding is the most significant approach for parts orientation and feeding in the actual production, which has been widely used in electronic components manufacturing and other fields. Based on the principle of its application, we have designed the demo device of industry application as shown in Fig. 2.

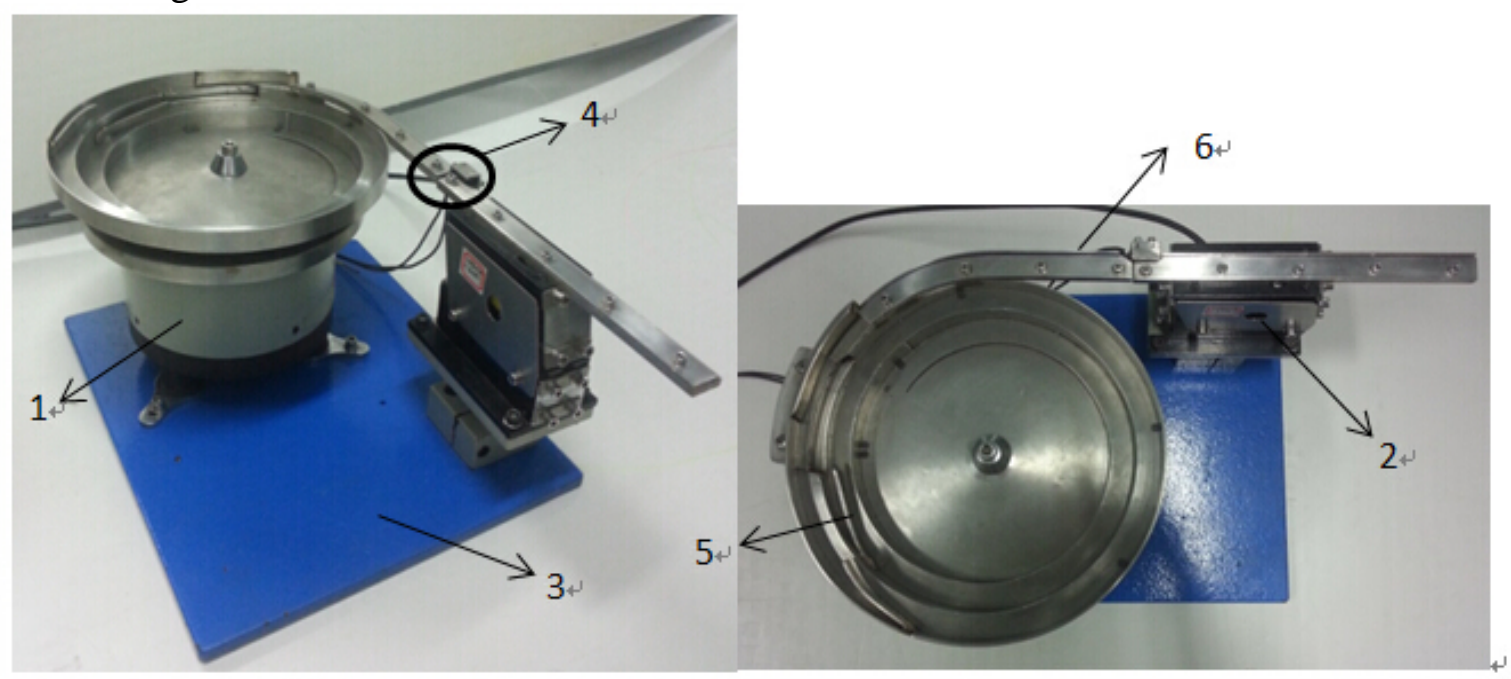

Fig.2 Structure of the demo device of industry application

Demo device of industry application consists of a vibratory bowl feeder (1 in Fig.2) and linear vibratory feeder (2 in Fig.2). They are all fixed on the bottom plate ( 3 in Fig.2), and achieve docking as shown in 4 of the Fig.2. When these feeders are driven, the work-pieces jog along the track of vibratory bowl feeder. In the process of upward motion, the work-pieces realize the automatic feeding and orientation due to the effect of orientating device as shown in 5 of the Fig.2. Then the bowl feeder puts the work-pieces into the linear vibratory feeder through the outlet (6 in Fig.2). Finally the spiral movement of the work-pieces is converted to linear motion by linear vibratory feeder. At the same time, linear vibratory feeder provides these parts with enough power to move forward, until they reach the next working procedure.

The overall dimension of the demo device of industry application is only $335 \mathrm{~mm} \times 285 \mathrm{~mm} \times 200$ $\mathrm{mm}$. Among them the diameter of vibratory bowl feeder is $160 \mathrm{~mm}$, the size of the bottom plate is 
$110 \mathrm{~mm} \times 40 \mathrm{~mm} \times 95 \mathrm{~mm}$. The overall structure of this device is lightweight and delicate. And controller can be used according to the customer's requirements. All in all, we have designed a device, which is a preferred instrument for demonstration of the industry feeder.

\section{Design of the demo device of working principle}

The main factors which influence the speed of vibratory feeder include: track angle $\alpha$, vibration angle $\beta$, frictional coefficient $\mu$, etc., among which the track angle $\alpha$ and vibration angle $\beta$ are adjusted by the design of mechanical structures. The demo device of working principle is designed in this paper as shown in Fig. 4.

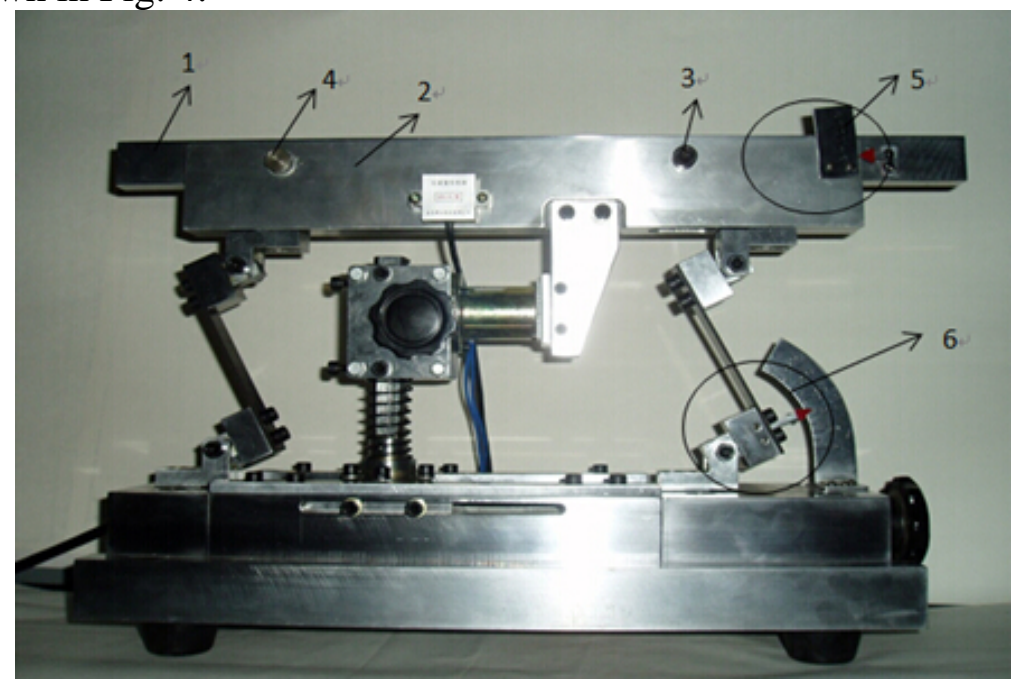

Fig.3 Structure of the demo device of working principle

The structural design of the demo device of working principle consists of track, leaf spring, armature iron, electromagnet, base. The track angle $\alpha$ is the angle of the transfer surface and the plane. The track is made up of inside track ( 1 in Fig.3) and outside track (2 in Fig.3). They are connected by the screw (3 and 4 inFig.3). So inside track (1 in Fig.3) can rotate around screw (4 in Fig.3) in a certain range. Meanwhile a connection part which is similar to hinge structure is designed, which makes the angle between leaf spring and base can be adjusted. The vibration angle $\beta$ is the angle between vibration direction of track and conveying surface. The angle cannot be adjusted directly, mainly adjusted by the spring angle $\gamma$ (6 in Fig.3) indirectly as the equation below: $\beta=\gamma-\alpha$.

\section{Conclusion}

This paper has designed a vibratory feeding system for teaching purpose, which is divided into two parts: one consists of the bowl and linear vibratory feeder, it is used for demonstrating applications of vibratory feeding in industry. The other provides the detailed explanation and demonstration of the principle of vibratory feeding, the parameters can be adjusted. Overall, this system fills the blank of teaching platform in vibratory feeding and has great market value.

\section{Acknowledgement}

This work is supported by NSFC, project NO.51275087.

\section{References}

[1] H.G. de Cock, Vibratory Feeder, Philips Technical Review, v24 (3) (1962) 84-95.

[2] G. Winkler, Analysing the Vibrating Conveyor, International Journal of Mechanical Sciences, v20 (1978) 561-570. 
[3] G. Winkler, Analysing the Hopping Conveyor, International Journal of Mechanical Sciences, v21 (1979) 651-658.

[4] S. Okabe and Y. Yokoyama, Study on Vibratory Feeders: Calculation of Natural Frequency of Bowl-Type Vibratory Feeders, ASME Journal of Mechanical Design, v103 (1981) 249-256.

[5] S. Okabe, et al. Vibratory Feeding by No sinusoidal Vibration-Optimum Wave Form, Journal of Vibration, Acoustics, and Reliability in Design, v107 (1985) 188-195.

[6] G. H. Lim, Vibratory feeder motion study using TurboC++ language, Advances in Engineering Software, v18 (1993) 53-59.

[7] G. H. Lim, On the conveying of vibratory feeder, Computers and Structures, v62 (1) (1997) 197-203.

[8] Gary P. Maul, M. Brian Thomas, A systems model and simulation of the vibratory bowl feeder, Journal of Manufacturing Systems, v16 (5) (1997) 309-314.

[9] Paul C.-P. Chao a, Chien-Yu Shen, Dynamic modeling and experimental verification of a piezoelectric part feeder in a structure with parallel bimorph beams, Ultrasonics, v46 (2007) 205-218.

[10]B.C.Wen, S.Y.Liu and Q.He, Theory and dynamic design method of mechanical vibration, Machinery Industry Press, 2001. 